delinquents in that case we do not know. Dr. Satterley professes his ignorance of the millibar. He may not have seen Prof. V. Bjerknes's work published in Washington, or the discussions that have taken place upon it in meteorological publications. $\mathrm{He}$ should not, however, complain if those whose scientific lives depend absolutely upon measures of the pressure of the atmosphere feel necessities which he does not share. If he himself is unaware of the literature of the subject, he can get the information which he seeks very simply by asking his colleague who is charged with the duty of expounding the important subject of dynamical meteorology in the University of Toronto just as he would ask a mathematical colleague if he came across an equation which he could not solve. No doubt the powers of ten are awkward, and those that are superfluous will pass away with practical use, but not before.

The general question of the reform of our system of weights and measures is raised again by the Ministry of Reconstruction in the report of Lord Selborne's Sub-Committee appointed to consider the methods of increasing home-grown food supplies in the interest of national security. One difficulty in the way of home-grown supplies to which the report directs attention is the chaos of different units and the divergence of standards of measurement for agricultural produce. The Sub-Committee proposes, therefore, that a uniform standard of weight should be laid down on which alone sales and purchases of agricultural produce, other than liquids and certain market-garden produce, should be legal; with standard measures also for liquids and of number for marketgarden produce habitually sold in that way. Now that the sale of produce is no longer between the local grower and the local shopkeeper, but is so organised that narcissus grown in Scilly may be sold as cutflowers in Aberdeen, the old conventional methods of sale by the habit of local pottle or basket are certainly out of date.

There is no doubt that selling by weight is the scientific mode of procedure, and for dealing with shiploads the only practicable method. Also for the final distribution of the stock to small purchasers weighing is the only satisfactory basis of a modern bargain. For the intermediate stage between the large producer and the small buyer the measure of capacity that is based upon convenient packing for transport is very serviceable. When produce must be put into saclas, or pots, or flats in order to get it to market it is in so handy a form for sale and so badly arranged for weighing that some scale of equivalents must come into vogue either by agreement or by law, and it should be the object of legislation to make that easy and not difficult; just as wherever beer is sold it must be sold by the barrel, whether the barrel contains 36 gallons or $6_{3}$ litres.

The really debatable point, however, about a revised scheme of selling produce by weight is what the standard of weight shall be. Here the ton and the pound are the rivals, just as the pound (in another sense) and the penny are rivals in decimal coinage. There is such a convenient bridge to the metric svstem through the ton that an English name for the 1kilogram would be the best solution. If anyone can produce a monosvilable that would be generally adopted as a designation of a weight of about $2.2 \mathrm{lb}$., the rest might be comparatively easv. "Kilo" is neither sufficiently euphonious nor sufficiently exclusive.

Sale by number is another matter with a great historv of its own, depending upon the art of bargaining. When we have got rid of long hundreds. and bakers; or booksellers' dozens, and scores which are not twenties, we might then agree that an immense NO. 2556 , VOL. IO27 amount of bookkeeping would be saved if net prices could be protected against the inroads of discounts for prompt cash, but that is probably as deep down in human nature as giving back a shilling for good luck when one sells a pig.

\section{FRUIT INVESTIGATIONS AT LONG ASHTON. ${ }^{1}$}

THE report of the Agricultural and Horticultural Research Station of the National Fruit and Cider Institute, Long Ashton, near Bristol, gives a record of the work done during the year and the changes in organisation brought about as the result of the war. Fortunately, the investigations still continue, though much of the time of the staff is devoted to the rvork of the Food Production Department; and, still more fortunately, arrangements are in progress whereby the station will be able further to develop after the war. On its establishment in 1903 the station had to be content with $i_{5}$ acres of land; since that date the area has gradually expanded until at the beginning of this year it was 28 acres. Most of the land, however, is now planted up with fruit or covered with buildings, and no new experimental work requiring land could be undertaken at the station itself. An opportunity for increasing the area of available land has recently occurred, and arrangements have been made whereby this is to be extended to 53 acres, while an option has been secured that will enable another 200 acres to be taken over if necessary. The director is to be congratulated on having made these arrangements for future developments,

The report consists of a series of papers by the director, Mr. B. T. P. Barker, and the staff, Messrs. Otto Grove, G. T. Spinks, A. H. Lees, and C. T. Gimingham. The subjects are varied; there are several pathological papers dealing with diseases or pests of fruit-trees, one on apple stocks, and another on cider-apple jelly. The production of jelly from apples involves many interesting problems, the chemistry of which is not fully understood. Cider apples and perry pears are not normally used for food in this country except in times of scarcity, when certain varieties are taken by the jam-makers, and to a less extent for dessert and cooking purposes. In the case of apples only the "sours" are used in this way, the "sweets" and "bitter-sweets" being exclusively reserved for cider. The "sours" contain a good deal of malic acid, the amount exceeding 0.45 per cent. in the juice; they yield a jelly without difficulty. The "sweets" and "bitter-sweets" have hitherto proved unsuitable for jelly-making, but $\mathrm{Mr}$. Barker has now fortunately discovered the proper conditions for manufacture. The juice is first extracted, and is then concentrated in a Kestner evaporator until the malic acid constitutes between $I$ and $I \cdot 5$ per cent. of the whole; then sugar is added until the total quantity present amounts to $6_{5}$ per cent. In practice a certain amount of blending of juices is desirable, so as to ensure that the proper concentration of malic acid shall be readily obtained. It is, of course, possible to obviate any addition of sugar by carrying the evaporation far enough; in this case it would have to go to one-seventh of the original value of the juice, the average sugar content of which is about io per cent. On the whole, it is found cheaper to add the sugar.

A prolonged investigation is being made into the various "stocks"-the seedling trees on which grafts are grown. Of these "stocks" there are great

1 Annual Report of the Agricultural and Horticultural Research Station National Fruit and Cider Institute, Long Ashton, Bristol, 1917. 
numbers, but $\mathrm{Mr}$. Barker proposes to treat them as a series of hybrid varieties produced by much natural inter-crossing, in the first instance between the botanical species from which the ordinary cultivated apple has arisen, and, later, between the varieties resulting from the earlier hybridisation. The main problem is to determine the nature of the influence of the stock on the resulting fruit-tree, and, in particular, whether it is simply mechanical in nature and regulated by the morphology of the root system, or whether there is a definite physiological influence, the nature of which is determined by the character of the seedling. If the latter is a factor, the problem is, of course, extraordinarily complicated, but there are opened up possibilities of strilking developments in the culture of fruit. Further work on this important subject will be awaited with interest.

\section{A NEW GRAI'HIC METHOD IN NAUTICAL ASTRONOMY.}

A NEW departure of some little interest has been A recently taken in America in the publication by the United States Hydrographic Department of a new chart, or diagram, for finding readily by a simple graphic process hour angle or azimuth at sea. So far as azimuth is concerned, a diagram of this nature, known as Weir's Azimuth Diagram, has been in use for many years, but in that case the hour angle is made use of as a datum, whereas in the new diagram the altitude takes the place of hour angle as argument; and, as an altitude can be observed at sea with much less trouble than hour angle can be deduced from chrononeter time. some labour is saved by its substitution.

The construction of the diagram, which is due to the inventive genius of Mr. G. W. Littlehales, of the U.S. Hydrographic Department, is based upon a function of the angle very generally employed by navigators, but not much known outside nautical circles, called the haversine. A formula very senerally employed in spherical trigonometry for finding an angle of a triangle from three sides given is

$$
\sin _{2} \mathrm{~A}=\frac{\sin (s-b) \sin (s-c)}{\sin b \sin c} \text {. }
$$

The practical application of this formula was very much simplified about a century ago by the introduction into the nautical text-books of a new table which gave the value of the logarithm of the square of the sine of one-half the angle, and was therefore called the "sine square" table. A little later, since

$$
\sin ^{2} \frac{A}{2}=\frac{1}{2}(1-\cos A)=\frac{1}{2} \text { vers } A \text {, }
$$

the name of haversine, or half versine, suggested itself for the new function of the angle, and as such it is generally known to-day.

The particular formula on which the diagram is based was proposed about ten years since, and is as follows :

$$
\text { hav }(a)=\operatorname{hav}(b \sim c)+\{\operatorname{hav}(b+c)-\operatorname{hav}(b \sim c)\} \text { hav A. }
$$

If the sides $b, c$ be regarded as constants, $a$, A being variables, this expression takes the form

$$
y=m x+c
$$

that is, of the equation to a straight line.

This formula suggested to the inventor the notion of a square chart, with sides graduated according to the values of a series of natural haversines, by means of which, having given the altitude and declination of a body and the latitude of place, hour angle and azimuth might be found by simple inspection. Upon such a chart, by drawing a straight line through two NO. 2556 , VOL. IO2] points readily determined, a connection would be established, in one case between the hour angle and zenith distance, in the other between azimuth and polar distance, so that, one of a pair being given, the value of the other could be taken approximately from the chart.

\section{The Triangle of Position in Nautical Astronomy.}

The diagram which follows exhibits on the flane of the horizon what is known as the "triangle of position," in which

$\mathrm{PZ}$, the co-latitude $\quad=90^{\circ}-$ lat. or $c$.

$\mathrm{PX}$, the polar distance $=90^{\circ} \pm$ dec. or $p$.

$Z X$, the zenith distance $=90^{\circ}-$ alt. or $z$.

ZPX, the hour angle $=$ H.

$\mathrm{PZX}$, the azimuth $=\underline{Z}$.

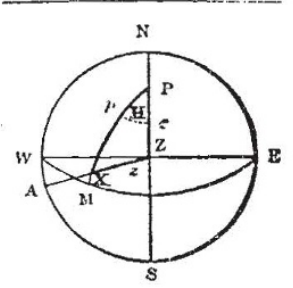

The general formula adapted to this triangle gives for hour angle.

hav $z-\operatorname{hav}(p \sim c)=\{\operatorname{hav}(p+c)-\operatorname{hav}(p \sim c)\}$ hav H, the polar distance $(p)$ and co-latitude $(c)$ being considered as constarits.

The small diagram given below will perhaps serve to explain the process adopted. The side is only 3 in. in length, compared with $2 \mathrm{ft}$. in that issued for practical use. In the actual chart, again, a svstem of "grillage," by means of lines drawn at short intervals parallel to the sides of the chart, enables the value of an angle to be read off to the fraction of a degree at sight, whereas in the small diagram the graduations of the sides are equal, and the points marked indicate the angles corresponding with successive values of the haversines at intervals of 0.125 .

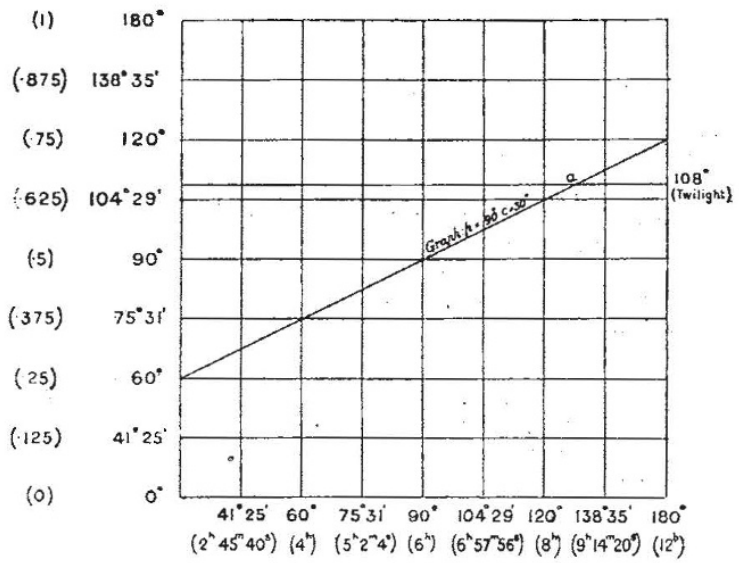

\section{Hour Angle and Zenith Distance.}

Example I.-At a place in lat. $60^{\circ}$, when the sun is on the equator, find zenith distance at 4 h. P.M., hour angle at setting, and at the end of twilight.

Rule.-On left-hand margin mark the point corresponding with $(p \sim c)$, i.e. of meridian zenith distance at upper transit, and on right-hand margin the point for $(p+c)$, or meridian zenith distance at lower 